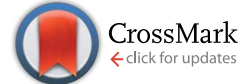

Cite this: Nat. Prod. Rep., 2016, 33, 920

\title{
Standardization for natural product synthetic biology
}

\author{
Huimin Zhao*a and Marnix H. Medema*b
}

Standardization is one of the foundational features of modern-day engineering, and the use of standardized

Received 8th March 2016 parts and processes is a key element that distinguishes bona fide synthetic biology from traditional genetic engineering. Here, we discuss the role of standardization in natural product synthetic biology, focusing on standardization of data on biosynthetic pathways and gene clusters, as well as the role of standardization in the process of biosynthetic gene cluster engineering.

\section{The importance of standardization for synthetic biology}

Our world is highly dependent on standardization. Almost any tool, machine or piece of equipment that we use in daily life conforms to certain standards; anyone who has ever forgotten his travel adapter when visiting a different continent will acknowledge this. Or imagine having to change a tire if all screws and bolts were of different shapes and sizes: standards are a key enabling feature for any engineering. This also clearly applies to biological engineering, or 'synthetic biology'. Already in 2005, Drew Endy highlighted the need for 'the development of technologies and the promulgation of standards that support the definition, description and characterization of the basic biological parts, as well as standard conditions that support the use of parts in combination and overall system operation'. ${ }^{1}$ This endeavor to standardize biological parts and provide standardized descriptions about whatever is variable about them remains a key tenet of synthetic biology. Arguably, standardization is one of the key elements that distinguish bona fide synthetic biology from traditional genetic engineering: by enabling modularity and interchangeability of parts, it elevates it from merely tinkering with natural biological systems to conceptual design-based engineering of novel biological devices from standardized parts.

\section{Standardization for natural product biosynthesis}

The recent revolution in genome sequencing enabling the discovery of thousands of biosynthetic gene clusters (BGCs), ${ }^{2,3}$

${ }^{a}$ Department of Chemical and Biomolecular Engineering, Carl R. Woese Institute for Genomic Biology, University of Illinois at Urbana-Champaign, Urbana, IL, USA. E-mail: zhao5@illinois.edu

${ }^{b}$ Bioinformatics Group, Wageningen University, Wageningen, The Netherlands. E-mail: marnix.medema@wur.nl the continued improvements in DNA synthesis and assembly technologies, ${ }^{4,5}$ and the development and refinement of gene cluster refactoring methods ${ }^{6}$ are opening up great opportunities to harness the power of synthetic biology to explore the chemical diversity found in nature. ${ }^{7}$ Moreover, it potentially allows expansion of this chemical diversity by combining biosynthetic parts (e.g., enzymes) from various known (and predicted) biosynthetic pathways. To facilitate this, accurate and standardized descriptions of these parts are required to allow searching, comparing and connecting parts with specific characteristics. As eloquently argued by Canton et al., ${ }^{8}$ each biological part should be described on a 'datasheet' that specifies current and up-to-date knowledge of its function. For regulatory parts, such as promoters and ribosome binding sites (RBSs), various large libraries have been characterized using standardized methodologies. ${ }^{9-11}$ However, until recently, standardized information on enzyme-coding genes, the biological parts most important for the design of natural product biosynthetic pathways, has been missing.

Recently, the Minimum Information about a Biosynthetic Gene cluster (MIBiG) initiative ${ }^{12}$ made important first steps in providing a data standard for natural product-acting enzymes and the pathways that they constitute. The MIBiG standard captures information about the genomic, enzymological and chemical information regarding a natural product biosynthetic pathway. To this end, it comprises over seventy different parameters. In order to cater to the unique characteristics of each class of biosynthetic pathways, a set of generally applicable parameters is complemented by several compound classspecific sets that can be used to provide details on biosynthetic pathways for the production of polyketides, nonribosomal peptides, terpenoids, ribosomally synthesized and posttranslationally modified peptides (RiPPs), saccharides, alkaloids and others. Moreover, the standard has been designed for compatibility with bacterial, fungal and plant biosynthetic pathways, even if they are encoded on multiple genomic loci instead of in one biosynthetic gene cluster. The MIBiG repository, which is 
available from http:/www.mibig.secondarymetabolites.org, now contains fully MIBiG-compliant descriptions of 418 BGCs and more minimal descriptions for another 879 BGCs. Thus, it provides comprehensive data on many biosynthetic pathways, and has the potential to function as a catalogue of enzyme parts for the design and engineering of biosynthetic pathways. Creating an interactive database with higher-level search functions to navigate these data will be a key next step in facilitating this function of MIBiG.

Despite its comprehensiveness, MIBiG itself does not cover all types of information that are relevant for natural product discovery. For example, to maximize the efficiency of environmental bioprospecting, detailed taxonomic and geographical information is very important. ${ }^{\mathbf{1 3 , 1 4}}$ Most of this information is well-covered by the MIXS specification ${ }^{\mathbf{1 5}}$ (of which MIBiG is in fact an extension), which covers items like geographical coordinates, biome type and taxonomy of the host organism (in case of a symbiotic origin).

To make standardization for natural products research a success, it will be essential that the entire community remains devoted to submitting information on newly published biosynthetic pathways, all in the same standardized format. This will not only help community to leverage this information in new pathway designs, but also increase the visibility of the published results themselves. The Protein Data Bank, a database containing standardized information on macromolecular crystal structures, is an excellent example of how standardization and centralized storage promote re-use of data, but also large-scale correction and refinement. ${ }^{16,17}$ Even if no fulltime salaried curators are available, this could still be done by crowdsourcing community involvement in curation/annotation hackathons or even by organizing large-scale and parallelized annotation efforts by undergraduate students. ${ }^{18}$

\section{How to achieve standardization I: evidence-coding and ontologies}

Standardization should not be seen as a way of forcing everybody to do everything in exactly the same way: not everything can or should be standardized. For example, different analytical techniques (such as NMR, mass spectrometry and X-ray crystallography) exist that enable the elucidation of the chemical structures of natural products. The chemistry and structural complexity of the molecule determines which analytical techniques are most useful, and each analytical technique has its own advantages and disadvantages; it would be unwise (and very unproductive) to prescribe the use of the exact same protocol for each type of molecule. Hence, for data items regarding the characterization of biological/biochemical parts that are variable for a good reason, a standardized description (or 'ontology') of the choice made is needed instead of a standardized prescription of the choice. For example, databases like the UniProt Knowledgebase ${ }^{19}$ uses the detailed 'Evidence Code Ontology', ${ }^{20}$ which specifies the type and level of evidence for each annotation item of a protein. Similarly, the MIBiG standard $^{12}$ uses an ontology of enzyme functions and substrate specificities, which includes a system of evidence codes to specify the various types of experimental methodologies that could provide the proof for a given annotation. In this case, such an evidence ontology makes it feasible to build simple tools to not only combinatorially search through these annotated enzymes and enzyme domains by function and substrate specificity, but also offering the possibility to filter search results by the level or type of experimental evidence.

Of course, when searching for biological parts to fulfill a function in a certain synthetic pathway, the search space can be extended from experimentally characterized pathways (e.g.,

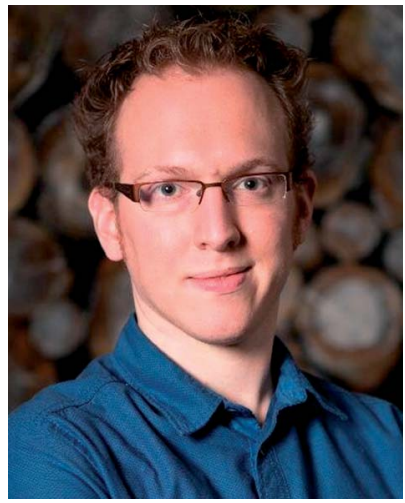

Dr Marnix Medema is an Assistant Professor of Bioinformatics at Wageningen University. He received his B.Sc. degree in Biology from the Radboud University Nijmegen in 2006, and his M.Sc. in Biomolecular Sciences at the University of Groningen in 2008. He obtained his PhD degree at the University of Groningen in 2013. During his PhD studies, he spent half a year at the University of California,

San Francisco, as a visiting scientist. Between 2013 and 2015, he was a postdoctoral fellow at the Max Planck Institute for Marine Microbiology in Bremen. In 2015, he joined Wageningen University, where his research group develops and uses state-of-the-art computational tools to understand specialized metabolism from a genomic perspective. 
as found in the MIBiG repository) to predicted BGCs in sequenced genomes. For this, computational predictions of enzyme function and substrate specificity can be exploited, to make it easy to create libraries of enzyme variants that have been selected by natural evolution to have different catalytic efficiencies and specificities; screening of such large libraries of synthetic enzyme-coding genes has been shown to be a highly effective method to optimize pathway function as a whole. ${ }^{21}$ Also for such predictions, the bioinformatics community should strive to supply standardized levels of prediction confidence, in order to distinguish 'vague guesses' from confident predictions. The NRPSPredictor2 tool, ${ }^{22}$ which predicts NRPS adenylation domain substrate specificities, provides a good example for this, as it does not only return raw predicted substrates, but also offers predictions at various levels (from single amino acids to hydrophobicity/hydrophilicity) and assesses the prediction resolution ('applicability domain') that is achievable for a given input. However, several other algorithms have recently been developed for the same purpose ${ }^{23-26}$ and this in turn requires standardized benchmarks to accurately compare their (sometimes conflicting) results. Potentially, standardized information on experimentally determined specificities from, for example, the MIBiG repository, could be used to assess at regular time intervals which algorithms perform best on which substrates and taxonomic groups. Moreover, recorded evidence quality could be taken into account to weigh the input data (for either testing or re-training) in such a case: e.g., NRPS adenylation domain substrate specificities determined by ATP/PPi exchange assays could be given more weight than specificities indirectly derived from natural product structures, as in the latter case the amino acid might have been modified after peptide release from the assembly line.

\section{How to achieve standardization II: pathway engineering}

One of the most effective synthetic biology strategies in natural product research is to reengineer or refactor the BGCs in heterologous hosts. ${ }^{27}$ For example, commonly used heterologous hosts such as Escherichia coli and Saccharomyces cerevisiae were used to produce artemisinic acid (a key precursor of antimalarial drug artemisinin), ${ }^{28}$ taxadiene (a key precursor of anticancer drug taxol), ${ }^{29}$ and opioid compounds thebaine and hydrocodone, ${ }^{30}$ as well as many analogs of some antibiotics such as erythromycin via combinatorial biosynthesis. ${ }^{31} \mathrm{~A}$ similar strategy was also used to activate silent BGCs from sequenced genomes. ${ }^{32}$ However, construction of a reengineered biosynthetic pathway is typically time-consuming and laborintensive. Recently, a wide variety of DNA assembly tools have been developed for rapid construction of large DNA molecules such as natural product biosynthetic gene clusters, ${ }^{6}$ which is allowing scale-up of this ground-breaking technology to characterize larger numbers of BGCs.

As this methodology to characterize BGCs and their products becomes more prominent, the process of (re-)engineering BGCs will also require standardized descriptions. After all, the design of the expression construct (including regulatory sites and possible codon optimization), the host used and the growth conditions may all influence the outcome: e.g., some variants of a natural product may be produced in higher amounts in one case compared to another. Potentially, such a standardized description of synthetic BGCs could be designed as an optional extension to the MIBiG framework, similar to how a list of parameters relevant to the built environment microbiome has recently been designed as an extension to MIxS. ${ }^{33}$ Additionally, standardized formats to report and store detailed analytical data on natural products will be highly useful. The centralized and standardized storage of mass-spectrometric data in GNPS (http://www.gnps.ucsd.edu/) is a very good step in this direction.

Standardization of the design procedures themselves may also facilitate full automation. For example, a fully automated Golden Gate method was developed to synthesize tailor-made transcription activator-like effectors on a large scale. ${ }^{34}$ With further optimization, these DNA assembly tools may facilitate the construction of any reengineered BGCs in a highthroughput manner. Also, a standardized syntax of parts (such as BioBricks ${ }^{35}$ ) and transcriptional units facilitates their worldwide exchange and re-use in different settings; for plant synthetic biology, such a comprehensive standard for transcriptional unit organization has recently been published. ${ }^{36}$

\section{Needs for future development}

Many further developments in standardization will be needed to facilitate effective and high-throughput (re-)engineering of natural product biosynthetic pathways. For example, due to the challenges in protein production in general and potential lack of precursors or cofactors in certain hosts, a panel of engineered hosts (chassis) optimized for heterologous production of natural products from different sources is required. For each engineered host, a set of well-characterized native or synthetic promoters and/or terminators should be developed. In principle, a target BGC should be expressed in a host that is evolutionarily closely related to its native producer. In addition, the processes for pathway engineering and characterization for each host should be standardized or even automated.

A key prerequisite for standard development is effective collaboration across the entire research field. The strength of working bodies like the Genomic Standards Consortium in effectuating standardization across the board lies in their open and inclusive nature, which allows all willing scientists to be coowners of the standards; if standards would be dictatorially imposed, there would be no intrinsic motivation for the scientists to implement and further update them. And the latter is of crucial importance: an effective standard should be a 'living' standard, which is continuously evaluated by the community itself as technology progresses; if this is not done, ontologies and other key features of the standard will be outdated very rapidly. Therefore, we invite the natural products community to join us in maintaining current standards and designing highquality extensions as the field of natural product synthetic biology further develops. 


\section{Acknowledgements}

We gratefully acknowledge financial support from VENI grant 863.15.002 from The Netherlands Organization for Scientific Research (NWO) (M. H. M.) and U.S. National Institutes of Health (GM077596) (H. Z.).

\section{References}

1 D. Endy, Nature, 2005, 438, 449-453.

2 P. Cimermancic, M. H. Medema, J. Claesen, K. Kurita, L. C. Wieland Brown, K. Mavrommatis, A. Pati, P. A. Godfrey, M. Koehrsen, J. Clardy, B. W. Birren, E. Takano, A. Sali, R. G. Linington and M. A. Fischbach, Cell, 2014, 158, 412-421.

3 J. R. Doroghazi, J. C. Albright, A. W. Goering, K.-S. Ju, R. R. Haines, K. A. Tchalukov, D. P. Labeda, N. L. Kelleher and W. W. Metcalf, Nat. Chem. Biol., 2014, 10, 963-968.

4 S. Kosuri and G. M. Church, Nat. Methods, 2014, 11, 499-507. 5 R. Chao, Y. Yuan and H. Zhao, FEMS Yeast Res., 2014, 15, 1-9. 6 R. E. Cobb, J. C. Ning and H. Zhao, J. Ind. Microbiol. Biotechnol., 2014, 41, 469-477.

7 M. J. Smanski, H. Zhou, J. Claesen, B. Shen, M. A. Fischbach and C. A. Voigt, Nat. Rev. Microbiol., 2016, 14, 135-149.

8 B. Canton, A. Labno and D. Endy, Nat. Biotechnol., 2008, 26, 787-793.

9 T. Siegl, B. Tokovenko, M. Myronovskyi and A. Luzhetskyy, Metab. Eng., 2013, 19, 98-106.

10 J. Blazeck and H. S. Alper, Biotechnol. J., 2013, 8, 46-58.

11 L. Zelcbuch, N. Antonovsky, A. Bar-Even, A. Levin-Karp, U. Barenholz, M. Dayagi, W. Liebermeister, A. Flamholz, E. Noor, S. Amram, A. Brandis, T. Bareia, I. Yofe, H. Jubran and R. Milo, Nucleic Acids Res., 2013, 41, e98.

12 M. H. Medema, R. Kottmann, P. Yilmaz, M. Cummings, J. B. Biggins, K. Blin, I. de Bruijn, Y. H. Chooi, J. Claesen, R. C. Coates, P. Cruz-Morales, S. Duddela, S. Düsterhus, D. J. Edwards, D. P. Fewer, N. Garg, C. Geiger, J. P. GomezEscribano, A. Greule, M. Hadjithomas, A. S. Haines, E. J. N. Helfrich, M. L. Hillwig, K. Ishida, A. C. Jones, C. S. Jones, K. Jungmann, C. Kegler, H. U. Kim, P. Kötter, D. Krug, J. Masschelein, A. V. Melnik, S. M. Mantovani, E. A. Monroe, M. Moore, N. Moss, H.-W. Nützmann, G. Pan, A. Pati, D. Petras, F. J. Reen, F. Rosconi, Z. Rui, Z. Tian, N. J. Tobias, Y. Tsunematsu, P. Wiemann, E. Wyckoff, X. Yan, G. Yim, F. Yu, Y. Xie, B. Aigle, A. K. Apel, C. J. Balibar, E. P. Balskus, F. Barona-Gómez, A. Bechthold, H. B. Bode, R. Borriss, S. F. Brady, A. A. Brakhage, P. Caffrey, Y.-Q. Cheng, J. Clardy, R. J. Cox, R. De Mot, S. Donadio, M. S. Donia, W. A. van der Donk, P. C. Dorrestein, S. Doyle, A. J. M. Driessen, M. EhlingSchulz, K.-D. Entian, M. A. Fischbach, L. Gerwick, W. H. Gerwick, H. Gross, B. Gust, C. Hertweck, M. Höfte, S. E. Jensen, J. Ju, L. Katz, L. Kaysser, J. L. Klassen, N. P. Keller, J. Kormanec, O. P. Kuipers, T. Kuzuyama, N. C. Kyrpides, H.-J. Kwon, S. Lautru, R. Lavigne, C. Y. Lee, B. Linquan, X. Liu, W. Liu, A. Luzhetskyy, T. Mahmud, Y. Mast, C. Méndez, M. Metsä-Ketelä, J. Micklefield,
D. A. Mitchell, B. S. Moore, L. M. Moreira, R. Müller, B. A. Neilan, M. Nett, J. Nielsen, F. O'Gara, H. Oikawa, A. Osbourn, M. S. Osburne, B. Ostash, S. M. Payne, J.-L. Pernodet, M. Petricek, J. Piel, O. Ploux, J. M. Raaijmakers, J. A. Salas, E. K. Schmitt, B. Scott, R. F. Seipke, B. Shen, D. H. Sherman, K. Sivonen, M. J. Smanski, M. Sosio, E. Stegmann, R. D. Süssmuth, K. Tahlan, C. M. Thomas, Y. Tang, A. W. Truman, M. Viaud, J. D. Walton, C. T. Walsh, T. Weber, G. P. van Wezel, B. Wilkinson, J. M. Willey, W. Wohlleben, G. D. Wright, N. Ziemert, C. Zhang, S. B. Zotchev, R. Breitling, E. Takano and F. O. Glöckner, Nat. Chem. Biol., 2015, 11, 625-631.

13 M. C. Leal, A. Hilário, M. H. G. Munro, J. W. Blunt and R. Calado, Nat. Prod. Rep., 2016, 33, 747-750.

14 Z. Charlop-Powers, J. G. Owen, B. V. B. Reddy, M. A. Ternei, D. O. Guimarães, U. A. de Frias, M. T. Pupo, P. Seepe, Z. Feng and S. F. Brady, eLife, 2015, 4, e05048.

15 P. Yilmaz, R. Kottmann, D. Field, R. Knight, J. R. Cole, L. Amaral-Zettler, J. A. Gilbert, I. Karsch-Mizrachi, A. Johnston, G. Cochrane, R. Vaughan, C. Hunter, J. Park, N. Morrison, P. Rocca-Serra, P. Sterk, M. Arumugam, M. Bailey, L. Baumgartner, B. W. Birren, M. J. Blaser, V. Bonazzi, T. Booth, P. Bork, F. D. Bushman, P. L. Buttigieg, P. S. G. Chain, E. Charlson, E. K. Costello, H. Huot-Creasy, P. Dawyndt, T. DeSantis, N. Fierer, J. A. Fuhrman, R. E. Gallery, D. Gevers, R. A. Gibbs, I. San Gil, A. Gonzalez, J. I. Gordon, R. Guralnick, W. Hankeln, S. Highlander, P. Hugenholtz, J. Jansson, A. L. Kau, S. T. Kelley, J. Kennedy, D. Knights, O. Koren, J. Kuczynski, N. Kyrpides, R. Larsen, C. L. Lauber, T. Legg, R. E. Ley, C. A. Lozupone, W. Ludwig, D. Lyons, E. Maguire, B. A. Methé, F. Meyer, B. Muegge, S. Nakielny, K. E. Nelson, D. Nemergut, J. D. Neufeld, L. K. Newbold, A. E. Oliver, N. R. Pace, G. Palanisamy, J. Peplies, J. Petrosino, L. Proctor, E. Pruesse, C. Quast, J. Raes, S. Ratnasingham, J. Ravel, D. A. Relman, S. AssuntaSansone, P. D. Schloss, L. Schriml, R. Sinha, M. I. Smith, E. Sodergren, A. Spo, J. Stombaugh, J. M. Tiedje, D. V. Ward, G. M. Weinstock, D. Wendel, O. White, A. Whiteley, A. Wilke, J. R. Wortman, T. Yatsunenko and F. O. Glöckner, Nat. Biotechnol., 2011, 29, 415-420.

16 C. Venclovas, K. Ginalski and C. Kang, Protein Sci., 2004, 13, 1594-1602.

17 R. P. Joosten, T. Womack, G. Vriend and G. Bricogne, Acta Crystallogr., Sect. D: Biol. Crystallogr., 2009, 65, 176-185.

18 Y. F. Li, K. J. S. Tsai, C. J. B. Harvey, J. J. Li, B. E. Ary, E. E. Berlew, B. L. Boehman, D. M. Findley, A. G. Friant, C. A. Gardner, M. P. Gould, J. H. Ha, B. K. Lilley, E. L. McKinstry, S. Nawal, R. C. Parry, K. W. Rothchild, S. D. Silbert, M. D. Tentilucci, A. M. Thurston, R. B. Wai, Y. Yoon, R. S. Aiyar, M. H. Medema, M. E. Hillenmeyer and L. K. Charkoudian, Fungal Genet. Biol., 2016, 89, 18-28.

19 M. Magrane, Uniprot Consortium, Database, 2011, p. bar009. 20 M. C. Chibucos, C. J. Mungall, R. Balakrishnan, K. R. Christie, R. P. Huntley, O. White, J. A. Blake, S. E. Lewis and M. Giglio, Database, 2014, p. bau075. 
21 T. S. Bayer, D. M. Widmaier, K. Temme, E. A. Mirsky, D. V. Santi and C. A. Voigt, J. Am. Chem. Soc., 2009, 131, 6508-6515.

22 M. Röttig, M. H. Medema, K. Blin, T. Weber, C. Rausch and O. Kohlbacher, Nucleic Acids Res., 2011, 39, W362-W367.

23 C. Prieto, C. Garcia-Estrada, D. Lorenzana and J. F. Martin, Bioinformatics, 2012, 28, 426-427.

24 B. I. Khayatt, L. Overmars, R. J. Siezen and C. Francke, PLoS One, 2013, 8, e62136.

25 D. Baranašić, J. Zucko, J. Diminic, R. Gacesa, P. F. Long, J. Cullum, D. Hranueli and A. Starcevic, J. Ind. Microbiol. Biotechnol., 2014, 41, 461-467.

26 M. Knudsen, D. Søndergaard, C. Tofting-Olesen, F. T. Hansen, D. E. Brodersen and C. N. S. Pedersen, Bioinformatics, 2016, 32, 325-329.

27 Y. Luo, B.-Z. Li, D. Liu, L. Zhang, Y. Chen, B. Jia, B.-X. Zeng, H. Zhao and Y.-J. Yuan, Chem. Soc. Rev., 2015, 44, 5265-5290.

28 C. J. Paddon, P. J. Westfall, D. J. Pitera, K. Benjamin, K. Fisher, D. McPhee, M. D. Leavell, A. Tai, A. Main, D. Eng, D. R. Polichuk, K. H. Teoh, D. W. Reed, T. Treynor, J. Lenihan, M. Fleck, S. Bajad, G. Dang, D. Dengrove, D. Diola, G. Dorin, K. W. Ellens, S. Fickes, J. Galazzo, S. P. Gaucher, T. Geistlinger, R. Henry, M. Hepp, T. Horning, T. Iqbal, H. Jiang, L. Kizer, B. Lieu, D. Melis, N. Moss, R. Regentin, S. Secrest, H. Tsuruta, R. Vazquez, L. F. Westblade, L. Xu, M. Yu, Y. Zhang, L. Zhao, J. Lievense, P. S. Covello, J. D. Keasling, K. K. Reiling, N. S. Renninger and J. D. Newman, Nature, 2013, 496, 528532.

29 P. K. Ajikumar, W. H. Xiao, K. E. Tyo, Y. Wang, F. Simeon, E. Leonard, O. Mucha, T. H. Phon, B. Pfeifer and G. Stephanopoulos, Science, 2010, 330, 70-74.
30 S. Galanie, K. Thodey, I. J. Trenchard, M. Filsinger Interrante and C. D. Smolke, Science, 2015, 349, 1095-1100.

31 H. G. Menzella, R. Reid, J. R. Carney, S. S. Chandran, S. J. Reisinger, K. G. Patel, D. A. Hopwood and D. V. Santi, Nat. Biotechnol., 2005, 23, 1171-1176.

32 Y. Luo, H. Huang, J. Liang, M. Wang, L. Lu, Z. Shao, R. E. Cobb and H. Zhao, Nat. Commun., 2013, 4, 2894.

33 E. M. Glass, Y. Dribinsky, P. Yilmaz, H. Levin, R. Van Pelt, D. Wendel, A. Wilke, J. A. Eisen, S. Huse, A. Shipanova, M. Sogin, J. Stajich, R. Knight, F. Meyer and L. M. Schriml, ISME J., 2014, 8, 1-3.

34 J. Liang, R. Chao, Z. Abil, Z. Bao and H. Zhao, ACS Synth. Biol., 2014, 3, 67-73.

35 R. P. Shetty, D. Endy and T. F. Knight Jr, J. Biol. Eng., 2008, 2, 5.

36 N. J. Patron, D. Orzaez, S. Marillonnet, H. Warzecha, C. Matthewman, M. Youles, O. Raitskin, A. Leveau, G. Farré, C. Rogers, A. Smith, J. Hibberd, A. A. R. Webb, J. Locke, S. Schornack, J. Ajioka, D. C. Baulcombe, C. Zipfel, S. Kamoun, J. D. G. Jones, H. Kuhn, S. Robatzek, H. P. Van Esse, D. Sanders, G. Oldroyd, C. Martin, R. Field, S. O'Connor, S. Fox, B. Wulff, B. Miller, A. Breakspear, G. Radhakrishnan, P.-M. Delaux, D. Loqué, A. Granell, A. Tissier, P. Shih, T. P. Brutnell, W. P. Quick, H. Rischer, P. D. Fraser, A. Aharoni, C. Raines, P. F. South, J.-M. Ané, B. R. Hamberger, J. Langdale, J. Stougaard, H. Bouwmeester, M. Udvardi, J. A. H. Murray, V. Ntoukakis, P. Schäfer, K. Denby, K. J. Edwards, A. Osbourn and J. Haseloff, New Phytol., 2015, 208, 13-19. 